\title{
A Irmandade Muçulmana Egípcia: aspectos transnacionais e nacionais de sua atuação política
}

\author{
The Egyptian Muslim Brotherhood: \\ national and transnational aspects \\ of its political performance
}

DOI: $10.21530 /$ ci.v11n1.2016.315

Danny Zahreddine ${ }^{1}$

Guilherme Di Lorenzo Pires²

\section{Resumo}

O artigo apresenta um balanço da história da Irmandade Muçulmana e sua relação com os sucessivos governos egípcios desde 1928, ano da criação da Irmandade por Hassan al-Banna. Uma abordagem histórica que vislumbre os caminhos políticos da Irmandade Muçulmana no decorrer das décadas mostra os processos que induziram mudanças significativas na agenda política da organização. Nas primeiras décadas de existência, a Irmandade Muçulmana era uma organização com vocação transnacional e engajada no combate ao colonialismo, ao imperialismo e ao regime egípcio, visto como corrupto e imoral. Para essas contendas, a organização desenvolveu uma ideologia militante e radical que encorajava ações drásticas, e até mesmo violentas. Contudo, desde o governo de Anwar Saddat, a Irmandade Muçulmana vem adotando uma postura diferente em relação à política, na medida em que ganhou legitimação social informal, ainda que não tenha recebido o reconhecimento legal. A partir desse momento, a Irmandade teve uma relação complexa com o regime egípcio, caracterizada por um ciclo de acomodação e coerção por parte do regime. Fatores políticos e sociais são fundamentais para a compreensão da mudança da agenda política da Irmandade Muçulmana,

1 Professor do Programa de Pós Graduação do Departamento de Relações Internacionais - PUC Minas.

2 Graduado em História pela UFMG. Mestrado em Relações Internacionais pela PUC Minas. E, atualmente, doutorando em Relações Internacionais pela PUC Minas.

Artigo recebido em 18/02/2016 e aprovado em 23/06/2016. 
de uma organização intransigente engajada nas questões regionais para uma organização que busca a aceitação institucional doméstica.

Palavras-chave: Transnacionalismo; Nacionalismo; Islã Político; Egito; Irmandade Muçulmana.

\section{Abstract}

This article presents an assessment of the history of the Muslim Brotherhood and its relationship with the successive Egyptian governments since 1928, year of foundation of the Brotherhood by Hassan al-Banna. An historical approach that follows the Muslim Brotherhood's political path through the decades shows the processes that have induced significant changes in the political agenda of the organization. During its first decades of existence, the Muslim Brotherhood was an organization with transnational vocation and engaged in combating colonialism, imperialism and the Egyptian regime, seen as corrupt and immoral. The organization has developed a militant and radical ideology that encouraged drastic, and even violent, actions. But it is argued here that since Anwar Saddat presidency, the Muslim Brotherhood has been adopting a different attitude to politics, as it gained a meaningful informal social legitimacy, but yet failed to secure legal recognition. From this moment, the Brotherhood has maintained a complex relation with Egyptian regime, characterized by a cycle of accommodation and coercion. In this aspect, political and social features are fundamental to understand the shift of the political agenda of the Muslim Brotherhood from an uncompromising organization engaged in regional affairs to one that searched domestic institutional acceptance.

Keywords: Transnationalism; Nationalism; Political Islam; Egypt; Muslim Brotherhood.

\section{Introdução}

O surgimento dos Estados nacionais na contemporaneidade representou um desafio para as autoridades religiosas e políticas nas sociedades de maioria muçulmana. O estabelecimento de Estados soberanos, com suas fronteiras definidas pelas potências europeias, colocou em xeque a noção da Umma - entendida como a comunidade de todos muçulmanos e que não reconhece distinções étnicas ou raciais - como uma categoria política relevante (AYOOB, 2008). A ideia de um sistema formado por nações, isto é, por comunidades políticas imaginadas como limitadas e soberanas (ANDERSON, 2008), representou um desafio tanto no sentido prático quanto ideológico às populações do Oriente 
Médio ${ }^{3}$ : qual deveria ser a base presumivelmente natural desses Estados nacionais? As respostas apresentadas pelo mundo islâmico foram diversas e contraditórias (AYOOB, 2008). O presente artigo analisa a maneira como a Irmandade Muçulmana egípcia ${ }^{4}$ se posicionou diante do princípio do nacionalismo, e como ela articulou essa ideia em ações políticas efetivas.

Abd al-Fattah El-Awaisi (1998) assinala dois fatores importantes para a compreensão da inserção da Irmandade Muçulmana na sociedade internacional ${ }^{5}$ do Oriente Médio: primeiro, há a ideia de que a Umma é a principal referência para a solidariedade coletiva. Nessa perspectiva, os motivos religiosos são constantes e invariáveis, pois derivam dos princípios básicos do Islã. O segundo aspecto são as realidades particulares nacionais as quais a Irmandade aceita como variáveis em função das condições históricas e sociais (EL-AWAISI, 1998). Com isso, Hassan al-Banna decompunha a lealdade política da Irmandade Muçulmana em três dimensões: a lealdade para com o país, para com o arabismo ${ }^{6}$ e para com o Islã. Contudo, a lealdade entre as três unidades não era percebida como conflitante nem contraditória, pois a interação entre os domínios teria como consequência a aproximação entre as unidades. Mas, dentro desses círculos concêntricos de identidades coletivas, o que se observa, no pensamento de al-Banna, é a primazia da comunidade dos fiéis sobre os demais.

Contudo, é preciso destacar que, na tradição islâmica, a Umma é mais do que uma comunidade política: ela abrange diversos elementos que dizem respeito à fé e à relação do homem e Deus. Com efeito, é possível pensar na Umma como uma comunidade puramente religiosa sem maiores implicações políticas. Contudo, fica evidente que a expectativa de al-Banna era que o estabelecimento de laços entre os fiéis os conduziria inevitavelmente a uma entidade política. O nacionalismo territorial, por sua vez, era um princípio válido, mas subordinado aos preceitos islâmicos, pois o nacionalismo teria uma finalidade "secular" e política (MITCHELL, 1969). Tendo em vista tal discussão, o presente artigo pretende explorar

3 Entre as diversas acepções do termo, no presente artigo a noção de Oriente Médio remete à região que se estende da costa oriental do Mediterrâneo até o Irã e da Anatólia central até a Península Arábica (ZAHREDDINE; LASMAR; TEIXEIRA, 2011).

4 No início do século XXI, a Irmandade Muçulmana possuía ramificações em mais de 70 países (MEIJER; BAKKER, 2012), o que faz da Irmandade uma organização bastante popular no Oriente Médio, além de ter sido o modelo para outros movimentos sociais e religiosos.

5 Emprega-se aqui o termo sociedade internacional tal qual elaborado por Barry Buzan (2004).

6 O arabismo foi um movimento político e uma ideologia moderna cujo objetivo primordial era o estabelecimento da Nação Árabe. O arabismo teve origem entre intelectuais da região do Levante na segunda metade do século XIX (HOURANI, 2006). 
determinados aspectos dessa problemática através da seguinte pergunta: qual o escopo da atuação da Irmandade Muçulmana no espaço nacional e no internacional?

É um estudo de caso que pretende apreender a maneira como um movimento islamista, a Irmandade Muçulmana egípcia, fez a passagem de um grupo transnacional para um grupo nacional. Nesse sentido, é proposto entender como os arranjos político-institucionais influenciaram a delimitação da agenda política e ideológica do grupo ao Estado egípcio. Desta forma, esboça-se a hipótese de que movimentos transnacionais com objetivos políticos, e buscando reconhecimento institucional, quando em Estados com aparato institucional político bem estabelecido, tendem a se nacionalizar, pois realidades políticas, sociais e históricas criam barreiras para ambições revolucionárias.

Para sustentar tal argumento, é proposto um estudo histórico da trajetória da Irmandade Muçulmana, observando o escopo da atuação política da organização. Nesse sentido, é importante observar que todos os processos políticos ocorrem na história, e consequentemente necessitam de um conhecimento dos contextos históricos em que estão situados. Assim sendo, a história é parte essencial da explicação de processos políticos.

Portanto, no estudo de caso, a perda de universalidade inerente às análises mais amplas é compensada pela apreensão de mecanismos causais, de sequências e combinações de variáveis. Se, por um lado, são abandonadas quaisquer pretensões de leis que expliquem grandes estruturas, análises mais detidas oferecem a oportunidade de entender mais profundamente processos locais, suas causas e suas trajetórias.

Nosso recorte temporal não alcançará com profundidade os desdobramentos atuais das revoltas que marcaram o Oriente Médio a partir de 2010 (Primavera Árabe), em particular no Egito (Revolução de Lótus), em 2011, por duas razões principais: a primeira, diz respeito ao longo espectro histórico, que por si só é capaz de reforçar a hipótese central do artigo. A segunda razão está ligada ao receio de se debruçar sobre um fenômeno tão recente, e ainda em transformação, o que poderia gerar análises equivocadas e imaturas sobre o processo em curso.

\section{Movimentos islamistas e o Estado}

A ascensão de movimentos islamistas no Oriente Médio vem sendo objeto de pesquisa e de discussões acadêmicas calorosas. No que diz respeito ao papel de fatores políticos, como mostra Annette Ranko (2015), a literatura sobre 
movimentos islamistas pode ser dividida em duas teses gerais: a tese da repressão e radicalização, e a tese da inclusão e da moderação.

A tese da radicalização se ampara na teoria dos movimentos sociais e pressupõe uma relação causal entre a repressão estatal sobre grupos islamistas e a radicalização desses. A abordagem da estrutura de oportunidade política prioriza o estudo do Estado, dos limites e das oportunidades políticas existentes, assim como a apreensão de fatores estruturais e institucionais que possibilitam a mobilização (WIKTOROWICZ, 2004). No caso desta abordagem, o acesso a instituições políticas (ou a falta dele) e a repressão estatal são as variáveis observadas. Porém, nem sempre a repressão estatal é acompanhada pela radicalização dos movimentos islamistas. Da mesma forma, existem casos em que movimentos se radicalizam sem uma condição incisiva de repressão.

Por outro lado, uma literatura importante na ciência política vem defendendo a integração de partidos políticos radicais dentro do sistema político, o que levaria à sua moderação. Esses partidos repensam seus princípios ideológicos tendo em vista a visibilidade eleitoral e a legalidade política. A moderação é entendida como a aceitação dos procedimentos democráticos. A participação nas políticas eleitorais leva, segundo tal perspectiva, à moderação da ideologia e à interiorização dos princípios democráticos (RANKO, 2015). Porém, há aqueles autores que afirmam que os movimentos islamistas usam a participação no sistema político como meio para a ascensão política, geralmente através de eleições. Nesse sentido, não há uma verdadeira aceitação dos princípios democráticos, mas um uso instrumental das eleições para se chegar ao poder (GURSES, 2014). Argumenta-se aqui que tais mecanismos que levam à moderação de movimentos islamistas são os mesmos que são responsáveis pela “nacionalização” desses movimentos.

Tendo isso em vista, a contribuição do presente artigo é chamar atenção para uma faceta que não é tão explorada: o escopo da atuação dos movimentos islamistas. Para tal exercício intelectual, adota-se uma noção mais geral conforme a proposta de Graham E. Fuller: islamista é aquele que “acredita que o Islã, enquanto corpo de fé tem algo importante a dizer sobre como a sociedade e a política devem ser ordenadas no mundo Muçulmano contemporâneo e busca implementar esta ideia de algum modo"7 (FULLER, 2010, p. 52, tradução nossa). Com isso, o termo abrange tanto movimentos nacionais quanto transnacionais, que são o objeto de pesquisa do presente artigo.

7 “(...) believes that Islam as a body of faith has something important to say about how politics and society should be ordered in the contemporary Muslim World and seeks to implement this idea in some fashion." 


\section{A criação da Irmandade Muçulmana}

A Irmandade Muçulmana foi fundada por Hassan al-Banna em 1928 no Egito. Hassan al-Banna nasceu em 1906 em uma região rural a nordeste de Cairo. O seu pai tinha formação religiosa, o que influenciou a vida espiritual de al-Banna, muito embora ele próprio não tivesse uma formação religiosa formal. Em 1923, al-Banna se mudou para o Cairo, onde teve contato com a ocidentalização da cultura egípcia, processo que ele considerou preocupante (COMMINS, 1994). Em 1927, al-Banna se juntou a outros jovens em uma sociedade que promovia o revivalismo islâmico, denominada a Associação dos Jovens Muçulmanos (COMMINS, 1994). Quando se graduou em 1927, o Ministério da Educação indicou Hassan al-Banna como professor de língua árabe na cidade de Isma’iliya, localizada no Canal de Suez e sede da administração da Companhia do Canal de Suez, lugar onde esteve próximo dos europeus que trabalhavam para a Companhia (COMMINS, 1994).

Em 1928, al-Banna fundou a Irmandade Muçulmana com o objetivo de promover aquilo que ele considerava constituir a essência do Islã. Nos quatro anos seguintes, outras ramificações foram criadas nas cidades vizinhas e na região do Delta. Em 1932, al-Banna decide mudar o centro da organização para o Cairo, e, a partir de então, o número de integrantes cresceu significativamente. Dez anos após a sua criação, a Irmandade contava com aproximadamente 50.000 membros e se tornara um dos movimentos sociais mais importantes no Egito (MITCHELL, 1969).

Como outros movimentos religiosos de sua época, a Irmandade Muçulmana, no início, era um movimento apolítico que buscava reformar a prática religiosa e prestar auxílio social aos seus integrantes. Contudo, as atividades da Irmandade se tornaram políticas ao final da década de 1930. O evento que precipitou tal mudança foi o protesto árabe na Palestina em 1936 contra o movimento sionista que ganhara fôlego no início daquela década. A Irmandade apoiou os protestos e militou pela causa Palestina entre a população egípcia. Ao mesmo tempo, a organização publicou críticas ao regime monárquico do Egito e à influência da Grã-Bretanha na política egípcia (MUNSON, 2001). Em 1941, as autoridades militares britânicas exigiram que al-Banna se retirasse do Cairo, e em outubro daquele ano, al-Banna e outros líderes da Irmandade foram presos e os encontros da organização foram banidos.

Além do engajamento político, a Irmandade Muçulmana também buscou estabelecer uma força paramilitar secreta. Hassan al-Banna via a causa Palestina sob a ótica religiosa, e mesmo antes da resolução da partilha do território sob a tutela britânica, a Irmandade Muçulmana dava grande importância à causa Palestina. 
Hassan al-Banna argumentava que os governos árabes deveriam financiar e armar as forças palestinas, mas não deveriam participar diretamente do conflito, pois assim evitariam o possível envolvimento de forças internacionais (EL-AWAISI, 1998).

A situação na Palestina precipitou outra tendência da Irmandade Muçulmana nas décadas de 1930 e 1940: a fundação de ramificações nos países vizinhos. Nesses anos, um intenso trânsito de pessoas e ideias tomou lugar entre a Irmandade Muçulmana e grupos religiosos na Síria e na Transjordânia. Em 1940, organizações religiosas sírias se uniriam sob o nome de Irmandade Muçulmana Síria, mantendo uma intensa relação com os membros egípcios, e, inclusive, durante a perseguição promovida durante o governo de Nasser, a Irmandade Muçulmana Síria desempenhou um papel importante.

Após conhecer uma fase de expansão no início da década de 1940, a Irmandade Muçulmana foi dissolvida no final de 1948 pelo governo egípcio sob o argumento de que a organização promovia a instabilidade nacional. Em resposta, a organização assassinou o primeiro-ministro egípcio Mahmud Fahmi al-Nuqrashi, responsável pela dissolução. Dois meses depois, Al-Banna foi morto pela polícia, encerrando, assim, a primeira fase da Irmandade Muçulmana (MITCHELL, 1969). No momento em que Hassan al-Banna morreu, a organização possuía entre 300.000 e 600.000 membros ativos, constituindo uma das maiores forças políticas e sociais organizadas no Egito (MUNSON, 2001).

Após o assassinato de Hassan al-Banna, a Irmandade entrou em um período de crise e de enfrentamento com o regime monárquico. Al-Banna foi substituído por Hasan Isma'il al-Hudaybi, juiz da Alta Corte e figura respeitada pela elite egípcia. E, apesar de não ser tão carismático quanto o seu predecessor, al-Hudaybi conseguiu garantir a sobrevivência do grupo durante os anos mais difíceis de sua história.

\section{O período de Nasser (1952-1970): momento de declínio da Irmandade Muçulmana}

Em julho de 1952, um grupo de jovens oficiais, sob a liderança do general Muhammad Naguib, derrubou o regime monárquico. Após um breve período de disputa interna, o coronel Gamal Abd Al-Nasser despontou como a figura forte no grupo e assumiu a presidência, cargo que ocupou até a sua morte, em 1970. Essas duas décadas constituíram o período mais crítico para a Irmandade Muçulmana em sua história. Nos seis primeiros meses de governo, os Oficiais 
Livres almejavam manter uma relação pacífica com a Irmandade, pois receavam a popularidade e a capacidade de mobilização do grupo. A Irmandade Muçulmana, por sua vez, apoiou a revolução, pois o novo regime se estabelecera em oposição ao imperialismo europeu e ao regime monárquico (MITCHELL, 1969). Entretanto, essa relação pacífica entre governo e a organização não durou muito. Logo surgiram tensões entre a Irmandade Muçulmana e a liderança do novo regime, sobretudo o coronel Gamal 'Abd al-Nasser.

Nasser buscou legitimar o seu governo através de políticas sociais e do nacionalismo secular ancorado no projeto pan-arabista. Ficava, então, evidente a incompatibilidade entre o projeto dos Oficiais Livres e o da Irmandade Muçulmana (GORDON, 1996). Ainda assim, é preciso observar que, apesar da desconfiança em relação à nova liderança de Hasan al-Hudaybi, Nasser tentou cooptar figuras importantes dentro da organização, inclusive oferecendo três ministérios a membros da Irmandade Muçulmana, os quais a liderança da Irmandade recusou (ZOLLNER, 2009).

Em 1954, um membro da Irmandade Muçulmana tentou assassinar Nasser durante um discurso público. Nasser respondeu ordenando novamente a dissolução da Irmandade e a prisão de centenas de membros. Os julgamentos subsequentes levaram à execução de líderes da irmandade (MUNSON, 2001). Nesse período, a Irmandade viu a liderança institucional de al-Hudaybi ser questionada por facções mais radicais do movimento que seguiam lideranças mais carismáticas, como o ideólogo Sayyid Qutb, que pregavam uma oposição mais radical ao regime de Nasser. A dissolução da Irmandade Muçulmana em 1954 marca uma nova fase na relação entre a organização e o regime que durou até 1967, quando os países árabes perdem a guerra para Israel. Durante esses anos, a Irmandade foi obrigada a agir de forma clandestina (ZOLLNER, 2009).

A Irmandade contava, nesse período, com o auxílio de membros que estavam no exílio e com o apoio de outras organizações similares naquela área. Atores externos, como a Arábia Saudita, que rivalizava com Nasser pela liderança na região, se tornaram fonte de recursos financeiros para a Irmandade. Evidências apontadas por Barbara Zollner (2009) mostram que a sobrevivência do grupo não se limitou a pequenos grupos no Cairo e em Alexandria, mas abarcava círculos que compreendiam outras partes do Egito.

Após alguns anos de uma liberdade controlada, em julho de 1965, o regime retomou as perseguições. Nesses anos, Nasser condenara a Irmandade sob a justificativa de que integrantes da organização estavam arquitetando um ataque 
armado com o intuito de derrubar o governo. As cortes sentenciaram à pena de morte diversos membros importantes, como Sayyid Qutb. Essa nova perseguição, apesar de ter sido tão dura quanto a de 1954, não colocou a existência do grupo em risco, pois, naquele momento, a organização da Irmandade estava mais estabelecida e havia um sentimento mais claro sobre a identidade da organização (ZOLLNER, 2009).

O que se pode observar nesses anos do governo de Nasser é a divisão entre setores mais radicais da Irmandade Muçulmana e a liderança moderada. Apesar de al-Hudaybi consentir com as atividades educacionais e os esforços de atualização da liderança ideológica realizados por Qutb, o líder da Irmandade buscou se distanciar da orientação mais radical vinculada ao combate da jahiliyya ${ }^{8}$. Desse modo, al-Hudaybi acabou sendo isolado pela fração jovem mais radical da organização, e foi considerado uma liderança fraca incapaz de guiar a Irmandade durante os anos de repressão (ZOLLNER, 2009). Hassan al-Hudaybi morreu em 1973, sendo sucedido por Urmar al-Tilmisani, proveniente de uma família importante de proprietários de terra, que liderou a Irmandade durante o regime de Sadat, fase caracterizada em seu início pela relativa cooperação entre a organização e o regime. Apesar de não ter sido um líder carismático, al-Hudaybi estabeleceu os fundamentos ideológicos adotados pelo grupo no início da década de 1970, rejeitando os preceitos radicais e militantes de Sayyid Qutb.

\section{Anwar Sadat (1970-1981): momento de reconstrução da Irmandade Muçulmana}

Logo após a morte de Nasser em 1970, o vice-presidente Anwar Sadat, um dos líderes da Revolução de 1952, assumiu o cargo de presidente. Sadat assumiu o governo de um país fragmentado e desmoralizado pela derrota na guerra de 1967. Sem o carisma de Nasser, Sadat se tornou uma figura política distinta de seu antecessor, não somente no aspecto pessoal, mas na postura política (IBRAHIM, 2002, p. 37). A busca por legitimidade levou Sadat a enfatizar o caráter religioso do governo e da sua própria pessoa (AYUBI, 1980). Para isso, ele endossava a construção de um Estado baseado nos valores islâmicos, ainda que não fosse um Estado teocrático no sentido estrito. Esse discurso ajudou a galvanizar a identidade islâmica do governo e da sociedade.

8 O termo Jahiliyya, conforme usado por Qutb, adquire o sentido da condição social e espiritual de qualquer sociedade que ignora a Sharia e a autoridade divina prescrita pelo Corão em todos os aspectos da vida (SHEPARD, 2003). 
Na busca por aliados no âmbito doméstico, Sadat se aproximou da Irmandade Muçulmana, mobilizando a lembrança de afinidades passadas para estabelecer tal aliança. Mas, ao mesmo tempo, Sadat adotava uma postura mais favorável aos Estados Unidos e às monarquias do Golfo, apontando para a nova posição do Egito na geopolítica do Oriente Médio (ZOLLNER, 2009). Esses dois elementos não se harmonizariam facilmente, o que constituiu um desafio para o governo de Sadat.

Ao passo que Nasser estabelecia sua legitimidade a partir do discurso de independência nacional, redistribuição de riqueza e defesa do nacionalismo árabe, Sadat utilizou a retórica do “direito” como fundamento de seu regime. Sadat se amparou no discurso de abertura das instituições estatais e no Estado de direito. E, realmente, Sadat consentiu abertura limitada aos oponentes do governo, mas, ao mesmo tempo, não permitia que eles tivessem acesso pleno ao poder. Nesse processo, o governo permitiu a criação de partidos alternativos para concorrer às eleições parlamentares de 1976. Todavia, o poder executivo do presidente suplantava as prerrogativas do Legislativo, além do governo acompanhar de perto a criação dos novos partidos. Por exemplo, não era permitida a criação de partidos baseados em afiliações religiosas, o que excluía a participação direta da Irmandade no poder (AYUBI, 1989).

Nesse ambiente, ainda que o poder fosse exercido de fato pelo partido do governo, grupos da oposição acolheram tal reforma com entusiasmo. Com isso, a Irmandade voltou a ser um ator importante no espaço público: se, por um lado, ela não poderia constituir um partido político, por outro, foi permitida à Irmandade empregar outros meios para expor suas ideias no espaço público e atuar abertamente na sociedade. Com a libertação de integrantes da Irmandade e a gradual abertura política, a Irmandade reconstruiu a organização e consolidou a sua presença no espaço público, rejeitando a ideologia mais radical da vertente de Qutb e aproximando-se dos preceitos defendidos por al-Hudaybi, que previa uma relação pragmática com as lideranças políticas (SULLIVAN, ABED-KOTOB, 1999). Desde então, um dos principais objetivos da irmandade é ser reconhecida como um movimento legal (AL-AWADI, 2004).

No âmbito internacional, o principal evento envolvendo o Egito foram os conflitos com Israel. Ao final da guerra em 1967, a ONU aprovou a Resolução 242 a fim de resolver o impasse entre Israel e os países árabes. Entretanto, Israel não cumpriu as diretrizes da Resolução, que previa a devolução dos territórios ocupados com a guerra, incluindo a Península do Sinai (ZAHREDDINE; LASMAR; TEIXEIRA, 2011). Nos anos após a guerra dos Seis Dias, houve o aumento das hostilidades 
entre Egito e Israel, e Sadat buscou negociar um acordo com Israel no início da década de 1970. O Egito estava disposto a reconhecer Israel como um Estado legítimo em troca da devolução da Península do Sinai. Porém, Israel se recusou a negociar sob o argumento de que o Sinai era um território fundamental para sua segurança. Diante dessa situação, o Egito e a Síria lançaram um ataque surpresa contra Israel, em 1973, no feriado judeu de Yom Kippur. A guerra evidenciou que o Egito ainda era um ator importante no Oriente Médio, e diante disso Israel aceitou iniciar as negociações de paz. Em 1978, ocorreram as negociações de Camp David, promovida novamente pelos Estados Unidos, que foram as bases para o acordo de paz de 1979 entre Egito e Israel (ZAHREDDINE; LASMAR; TEIXEIRA, 2011). No final desse processo, Israel retirara suas tropas do Sinai e o Egito, por sua vez, reconheceu Israel como um Estado soberano.

Contudo, a despeito dos ganhos políticos no cenário internacional, no cenário doméstico o regime passou a ser contestado, sobretudo por movimentos islamistas insatisfeitos com a relativa aproximação do Egito com Israel. Em 1974, houve uma tentativa de ataque em uma academia militar no Egito, promovida pelo grupo Shabab Muhammad. A reação do governo foi prender os líderes da organização e sentenciar alguns à pena de morte. Em resposta, o grupo Takwir wa-Hijra sequestrou o ministro de Questões Islâmicas, Sheikh Mohammad AlDhahabi, assassinando-o em junho de 1977.

Nos anos finais do governo de Sadat, a relação entre a organização e o governo foi bastante tensa, muito embora não chegasse aos níveis de embate entre o regime e grupos tais como o Jihad Islâmica e o Takwir Al-Hijra (BAKER, 1990). Tanto ou mais do que o fracasso de Sadat em abrir completamente o espaço político à participação pública irrestrita, o processo de paz de 1977 e a reconciliação com Israel com o acordo de Camp David foram os motivos das críticas dirigidas ao governo egípcio. Mas, mesmo com toda essa discordância, a Irmandade se manteve distante das ações violentas.

A atmosfera de tensão entre Sadat e a oposição ganhou uma nova dimensão em setembro de 1981, quando jornalistas, políticos e outras figuras importantes foram presos. Um mês depois, em 6 de outubro de 1981, um integrante do grupo Al-Jihad, sob a liderança de Abd Al-Salam Faraj, assassinou o presidente Sadat durante uma parada militar. A Irmandade Muçulmana, por sua vez, se distanciou dos grupos radicais e lamentou publicamente o assassinato, evidenciando os novos rumos que a organização tomara a partir do governo de Sadat. 


\section{Era Hosni Mubarak: um panorama da dinâmica política até as eleições de 1995}

As relações entre a Irmandade Muçulmana e o governo de Mubarak, que subiu ao poder após a morte de Sadat, podem ser divididas em duas fases: a primeira, que vai de 1981 a 1990, foi um período de acomodação e relativa tolerância. Nesse momento, Mubarak promoveu uma série de políticas que visava fortalecer a legitimidade do regime. Por um lado, Mubarak buscou se aproximar dos demais países árabes e restringiu o diálogo com Israel. Por outro, fortaleceu a noção do Estado de direito e abriu espaço para maior atividade da imprensa. $\mathrm{O}$ segundo período, de 1990 adiante, foi um período de crise econômica e política, que desencadeou uma escalada de confronto e repressão.

A fragilidade econômica levou a uma crescente intervenção e manipulação do governo na Assembleia e em outras arenas políticas. O regime havia aceitado a decisão da Suprema Corte Constitucional, que considerara as eleições de 1987 inapropriadas, dissolvendo, assim, a Assembleia e convocando novas eleições para 1990. Com isso, o regime tentava mostrar à população e ao mundo que o Egito caminhava rumo a um período "pós-autoritário”. Mas a oposição, incluindo a Irmandade Muçulmana, criticou duramente essa decisão e boicotou as eleições de 1990, abalando a credibilidade do regime (AL-AWADI, 2004).

Outro elemento que ajudou a abalar a imagem do regime na década de 1990 foi a crescente confrontação com grupos radicais. Em 1992, a atuação de extremistas religiosos coincidiu com a ascensão dos islamistas na Argélia e o assassinato do presidente argelino Muhammad Boudiaf (AYALON, 1992). A intensificação da violência extremista religiosa estava vinculada à frustração de diversos setores da população em relação ao regime. O resultado desse conflito foi a escalada de violência, na medida em que agressões contra o Estado incitaram uma resposta radical por parte do governo, que não distinguia mais islamistas radicais e moderados (BURGAT, 2005). Diante de tal cenário, a Irmandade optou pelo caminho da preservação da reputação pública ${ }^{9}$.

Assim, em um contexto de ausência de plataformas políticas formais, a Irmandade direcionou o ativismo a diversos espaços sociais, tais como os sindicatos e universidades, que serviam como plataformas efetivas e como alternativas ao sistema político desigual que negava a participação. Além disso, a Irmandade

9 Gilles Kepel (2003) considera a formação dos grupos islamistas radicais contemporâneos como consequência da renúncia às ações violentas pela Irmandade Muçulmana na década de 1970. 
soube representar, de maneira bem articulada, os anseios da classe média baixa que estava insatisfeita com o governo de Mubarak (AL-AWADI, 2004). Portanto, na falta de meios institucionais, a Irmandade Muçulmana buscou fortalecer sua posição política através da sua força social.

A tendência em transformar a legitimidade social em legitimidade legal, e a mobilização envolvida no processo, foi manifesta também nas tentativas sem sucesso de estabelecer partidos políticos, tais como o Hizb Al-Wasat. Além disso, representantes da Irmandade Muçulmana tentavam participar das eleições como candidatos independentes, além de terem forjado alianças com outros partidos políticos, como o partido liberal secular Wafd. Dessa forma, fica evidente o crescente pragmatismo da Irmandade Muçulmana, na medida em que ela buscou articular alianças políticas com grupos de ideologias distintas.

Portanto, o principal elemento que levou ao conflito entre a Irmandade Muçulmana e o regime de Mubarak foi a busca da Irmandade pela legitimidade, e a insistência da organização em competir com o regime em seu próprio terreno político (AL-AWADI, 2004, p. 177). Contudo, em 1991, um evento internacional contribuiu para a intensificação da oposição entre Irmandade e o regime: a primeira guerra do Golfo.

A posição regional e internacional egípcia era confortável até o início da crise do Golfo em agosto de 1991. Cairo continuava a consolidar a sua posição influente entre os países árabes, usufruindo o status de conciliador, especialmente com a Síria. Simultaneamente, o regime de Mubarak buscou incrementar as relações com a ainda existente União Soviética. O tratado de paz com Israel foi mantido, apesar de momentos de tensão entre Egito e Israel (AYALON, 1992). Se, por um lado, a crise do Golfo representou um divisor de águas no cenário internacional, no âmbito doméstico egípcio, o ano de 1990 foi, em grande parte, de continuidade, apesar dos impactos da crise. O que se observa é a continuidade nas questões políticas, sociais e econômicas (AYALON, 1992). A crescente pobreza e a ausência de perspectivas produziram tensões sociopolíticas e iniciou um período de violência.

Diante da reação internacional e da consequente Guerra do Golfo, o Comitê para a Ação dos Sindicatos - uma coordenação dos sindicatos sob influência da Irmandade - condenou a presença ocidental no Golfo Pérsico e considerou que o governo egípcio era responsável pela segurança dos egípcios que trabalhavam no Iraque e no Kuwait. Em uma segunda declaração, assinada no nome dos mesmos sindicatos, o Comitê condenou duramente o envolvimento do Egito na guerra, e reivindicou o retorno imediato das forças armadas (KEPEL, 2002). Contudo, 
a Irmandade Muçulmana egípcia não se envolveu em maiores manifestações públicas em defesa do Iraque.

Ao contrário da revolta palestina em 1936, evento internacional que incitou a politização da Irmandade Muçulmana, a primeira guerra do Golfo não representou um divisor de águas para a organização, que naquele momento estava completamente imersa na política doméstica. Obviamente, são eventos situados em contextos históricos distintos, mas não deixa de ser ilustrativo a comparação entre os dois episódios e a reação política da organização. No primeiro caso, a Irmandade se empenhou numa atividade transnacional pela união dos árabes em defesa da causa Palestina. No segundo momento, embora a Irmandade tenha participado de conferências internacionais e tenha mobilizado manifestações populares, esse engajamento não resultou numa postura mais assertiva por parte da organização nem redirecionou os principais pontos da agenda política, dedicada à busca da legitimidade interna.

Além disso, ao se observar as ramificações da Irmandade Muçulmana em outros países da região, é possível perceber a tendência das organizações a se mesclarem à dinâmica política dos respectivos países, ao ponto de cada ramificação adotar agendas distintas e autônomas. A Guerra do Golfo apresenta um caso emblemático de tais diferenças: ao passo que a Irmandade Muçulmana Egípcia mobilizou-se a favor de Saddam Hussein, a ramificação no Kuwait se opôs ao líder iraquiano. E cabe lembrar que a própria Irmandade Muçulmana do Iraque foi um dos principais aliados da invasão estadunidense, pois a ditadura de Saddam Hussein oprimia radicalmente toda a oposição (MEIJER; BAKKER, 2012).

\section{A Irmandade Muçulmana na Síria: uma breve comparação}

Uma breve comparação com a origem e a trajetória da Irmandade Muçulmana na Síria serve como caso ilustrativo do argumento aqui apresentado. A ramificação da Irmandade Muçulmana na Síria era um movimento autônomo da matriz egípcia, ainda que se inspirasse nas doutrinas de Hassan al-Banna. Tal autonomia foi fruto das particularidades sociais e políticas da Síria, as quais propiciaram uma trajetória histórica bastante distinta da organização egípcia (LEFEVRE, 2013). Além disso, cabe ressaltar que a Irmandade Muçulmana Síria se diferenciava internamente dependendo da região e das cidades nas quais ela se encontrava. Em Alepo, por exemplo, predominava uma vertente mais liberal, ao passo que em Hama se encontrava uma facção mais radical e violenta (LEFEVRE, 2013). 
Foi em Hama onde explodiu a revolta de 1982 liderada pela Irmandade contra o regime de Hafez al-Assad. A rebelião foi brutalmente reprimida e boa parte dos integrantes da Irmandade Muçulmana foi perseguida, presa e exilada. Com isso, a organização praticamente deixou de ter importância política nos anos seguintes. Ela só voltaria a ter um papel relevante na Síria a partir dos anos de 2000, quando a liderança em exílio da Irmandade buscou se aproximar do regime de Bashar al-Assad, mas rompendo novamente a relação a partir do conflito interno em 2011 (LEFEVRE, 2013).

Apesar da Irmandade Muçulmana egípcia ter desempenhando um papel ideológico e simbólico na formação da Irmandade síria, ela nunca teve controle absoluto sobre as ações e a administração de sua irmã. Isso porque a Irmandade na Síria não foi apenas uma ramificação da matriz, mas foi a união de inúmeros grupos religiosos já existentes no Levante. Esses grupos, anteriormente autônomos, foram unificados por integrantes que haviam visitado o Egito, onde entraram em contato com a ideologia da Hassan al-Banna. (TEITELBAUM, 2011). Portanto, pode-se dizer que a ideologia da Irmandade Muçulmana desempenhou um papel mais aglutinador do que realmente criador.

Ao contrário da organização egípcia, que contava com amplo apoio popular, a vertente síria era apenas um partido, entre vários, e nunca conseguiu estabelecer uma rede difundida na sociedade. Os integrantes da Irmandade Muçulmana Síria eram limitados à classe média urbana sunita e homens da religião, o que contribuiu para que o apelo da organização fosse limitado. Interessante notar que, ao contrário do Egito, a Irmandade Muçulmana Síria buscou apoio dos ulemás e das instituições tradicionais da religião, evidenciando seu distanciamento de movimentos mais populares (WEISMANN, 2010).

Uma outra diferença, ideológica, entre a Irmandade Muçulmana síria e a egípcia diz respeito ao lugar das minorias religiosas. No caso da organização egípcia, as referências ao cristianismo estavam associadas ao imperialismo europeu na região. Em contraste, a realidade social na Síria, caracterizada por um quadro étnico e religioso mais complexo e diverso, favoreceu uma visão mais nuançada do cristianismo (e das diversas minorias). Nesse caso, a ramificação síria adotou um discurso menos sectário e relativamente mais inclusivo que entendia o Islã como uma civilização no seio da qual diversas tradições e comunidades coexistiram. Em consonância com a tradição intelectual do Levante no início do século XX, a Irmandade Muçulmana Síria manifestava uma postura arabista mais forte que aquela expressada pelos seus colegas egípcios (TEITELBAUM, 2011). 
Por outro lado, pode-se apontar uma postura calculista e racional da Irmandade Muçulmana em adotar um discurso menos sectário, uma vez que as pretensões políticas da organização a levou a adotar um compromisso com um eleitorado mais diverso. Logo em 1947, a Irmandade Muçulmana Síria participou das eleições parlamentares e em 1949 das eleições para a assembleia constituinte. Diante das ambições de galgar ao poder através de eleições, a Irmandade precisava contar com os votos de cristãos e judeus (e outros grupos) (TEITELBAUM, 2011; WEISMANN, 2010). Essa tendência da Irmandade Muçulmana Síria em participar das eleições continuou até 1963, quando houve o golpe na Síria, que mais tarde levaria ao poder o partido Ba'th. Neste intervalo, a Irmandade deu origem a um partido político que participava ativamente da vida política síria.

\section{Os Aspectos Transnacionais e Nacionais da Irmandade Mulçumana}

O estudo da trajetória histórica da Irmandade Muçulmana ajuda a compreender os rumos que o grupo tomou em resposta aos contextos nacional e internacional. Comparando o cenário doméstico e o regional é possível observar um processo de “nacionalização” da Irmandade Muçulmana. Isto é, no decorrer das décadas, fatores internacionais passaram a exercer uma influência relativamente menor em comparação aos fatores domésticos. No início do século XX, a presença britânica e o movimento sionista foram fatores que retroalimentaram a identidade e a existência da Irmandade. Portanto, tal período é caracterizado pelo seu aspecto mais transnacional. No decorrer do século XX, os fatores domésticos sobrepujaram as variáveis externas, de modo que a Irmandade Muçulmana Egípcia gradualmente foi restringindo a sua atuação ao território egípcio. Nessa condição, ainda que a dinâmica internacional seja de extrema importância, acentuando ou retardando o processo em andamento, ela própria é filtrada pelas condições nacionais. Mas como entender tal mudança ocorrida na ação política da Irmandade Muçulmana?

Particularmente importante é o arranjo político introduzido com o Estado moderno, que teve papel fundamental na demarcação da agenda política do grupo. De modo geral, a Irmandade Muçulmana está inserida numa cadeia de movimentos religiosos que vinham atuando no Egito desde o século XIX. Contudo, essa longa tradição foi radicalmente alterada com a introdução do Estado moderno, o qual moldou o espaço de atuação política. Com isso, se elementos culturais permaneceram, o modo e a intensidade como foram mobilizados dependeram amplamente dos processos de modernização política. 
John Breuilly (1993) argumenta que uma das consequências do espaço político introduzido pela modernidade é a exigência de que elementos culturais se articulem de maneira a fazer sentido politicamente. Isto é, "a menos (e até) que essas ideias se 'fixem', por se tornarem parte de um movimento político que tem que negociar com governos e granjear apoio na sociedade, elas tendem a ser vagas e descontínuas" (BREUILLY, 2000, p. 170). O que se observa no caso da Irmandade Muçulmana é reflexo desse processo. No princípio, a Irmandade era um movimento social que abarcava um espectro amplo de ideias. Assim permaneceu nos primeiros anos, quando os círculos de identidade eram mobilizados de forma bastante ambígua. Contudo, a realidade política do Egito obrigou a Irmandade Muçulmana a articular as suas ideias de maneira que elas fizessem sentido politicamente para um determinado público. Com isso, o argumento nacionalista aos poucos foi se impondo à Irmandade, ainda que não de forma absoluta. John Breuilly (2000) chama atenção para o fato de que a ação política nacionalista tende a criar um conjunto mais coerente de doutrinas e sentimentos. As exigências da ação política, seja ela de movimentos oposicionistas ou dos governos, disciplinam as ideias e as direcionam para objetivos práticos, assim como canalizam sentimentos difusos numa direção particular. Desse modo, é possível perceber como a Irmandade Muçulmana, no decorrer do século XX, assumiu uma agenda política que, mesmo se opondo ao regime, continha pressupostos políticos e intelectuais compartilhados pela liderança política do Egito. A Irmandade Muçulmana passou a contestar o regime egípcio em nome da própria nação egípcia.

Talal Asad (1999), ao estudar a relação entre secularismo e religião nos espaços políticos nacionais, chama atenção para o fato de que, hoje, todo muçulmano habita um mundo diferente daquele vivido pelos fiéis do período clássico. Mesmo o mais conservador dos muçulmanos se ampara em experiências do mundo contemporâneo para aferir coerência às interpretações teológicas. Talal Asad considera que os islamistas estão, de diversas maneiras, próximos aos nacionalistas, mesmo que a doutrina do nacionalismo não encontre nas doutrinas teológicas clássicas algum conceito equivalente ao nacionalismo moderno. Os islamistas buscam atuar através dos Estados nacionais, os quais se tornaram entidades políticas centrais após a expansão da sociedade internacional europeia na contemporaneidade. Para Talal Asad é exatamente este projeto "estadocêntrico", e não uma suposta fusão de religião e política inerente ao Islã, que confere o caráter nacionalista aos grupos islamistas. Portanto, a preocupação dos islamistas com o poder do Estado não é um comprometimento a priori com ideais políticos nacionalistas, mas é uma 
resposta às delimitações colocadas pela reivindicação do Estado nacional moderno de constituir a arena e a identidade social legítima (ASAD, 1999).

Desenvolvendo um argumento semelhante, Olivier Roy (2012) introduz o termo “pós-islamismo” para os grupos que abandonaram, diante das novas realidades políticas e sociais, a ambição utópica de instaurar um “Estado islâmico”. Uma das opções adotadas por esses movimentos islamistas foi a adoção do partido político moderno como meio de defender os seus interesses. Isso implica a aceitação das regras institucionais do espaço político moderno. Ou seja, os partidos islamistas se transformam em puros partidos políticos, interiorizando as regras do Estado moderno, participando de eleições ou se aliando a outros partidos de ideologias políticas diversas, a fim de exercer influência no aparato estatal. A outra opção adotada foi a “radicalização” e contestação da política moderna. Olivier Roy (2012) mostra que as ramificações da Irmandade Muçulmana em outros países possuem suas próprias agendas nacionais, e, apesar da proximidade ideológica entre elas, as ramificações não apresentam uma estratégia regional coesa (ROY, 2012).

Nessa perspectiva, a obra de John Breuilly (2000) ajuda a compreender o caráter ambíguo e utópico de qualquer ideologia, e da transformação que ela passa diante da realidade política. A partir da metade do século XX, após o processo de descolonização e do fim da influência britânica, a Irmandade não mais se opunha a uma potência externa, mas ao próprio Estado egípcio. Diante desse cenário, a Irmandade teve duas reações distintas, uma que optou pelo radicalismo sectário, que não buscou mobilizar a comunidade egípcia como um todo. Por outro lado, a liderança escolheu o caminho do compromisso com o povo egípcio como meio de garantir a reputação pública e a realização de seu projeto, muito embora tal compromisso não se traduzisse em uma visão de mundo pluralista. Dessa forma, a mobilização social e coordenação política são dois aspectos fundamentais na compreensão da atuação da Irmandade Muçulmana ao longo do século XX.

Portanto, argumenta-se aqui que as mudanças pelas quais passaram os diversos movimentos islamistas no Oriente Médio não podem ser atribuídas a um único fator. Processos de mudança são o resultado da intervenção de inúmeras variáveis, internas ou externas aos grupos analisados. O estudo de caso ajuda a iluminar a maneira como tais fatores interagem entre si em determinadas circunstâncias históricas. Tendo isso em vista, é possível apontar alguns fatores relevantes.

O primeiro fator é a composição dos movimentos sociais. É preciso estar atento para a diferença entre gerações e para a heterogeneidade dentro da Irmandade Muçulmana. Esses aspectos implicam mudança de interesses, objetivos 
e interpretações de acordo com cada geração e de acordo com as divisões internas à organização. Através do estudo da composição social dos movimentos e de como é distribuído o poder internamente, é possível observar que grupos progressistas alcançam a liderança em alguns casos, em outros, não. No caso da Irmandade Muçulmana, a ala mais radical foi perdendo espaço a partir da segunda metade do século XX em benefício do setor pragmático. Contudo, os líderes mais reformistas nunca ocuparam os mais altos escalões da organização. As decisões da organização são tomadas pelos “conservadores pragmáticos”. Carrie Rosefsky Wickham (2013) demonstra como o processo de reforma e moderação da Irmandade Muçulmana pode ser entendido, em parte, como resultado do embate de uma liderança mais jovem em substituir a "velha guarda".

O segundo fator é a natureza da relação entre movimento e governo. A maior ou menor abertura, a solidez das instituições, os canais de comunicação existentes, a legitimidade do governo, todos estes aspectos informam as estratégias e as preferências dos movimentos. Os primeiros momentos de perseguição da Irmandade Muçulmana pelo Estado egípcio corresponderam aos momentos de maior radicalização. Os períodos de abertura criaram espaço para que a Irmandade buscasse a legitimidade institucional e o reconhecimento legal enquanto partido político.

O terceiro fator é o modo como os movimentos estão inseridos na sociedade como um todo. A Irmandade Muçulmana sempre se relacionou com outras organizações sociais, seja no Egito ou no exterior. Mas a busca pela legitimidade política, forma encontrada para promover os interesses da organização, implicou uma relação mais profunda com a sociedade egípcia e seus diversos grupos. Ainda que representasse uma fração considerável da sociedade egípcia, a Irmandade não possuía meios para, sozinha, chegar ao poder. A opção pelo meio institucional implicou a aproximação a grupos distintos e a coordenação de interesses entre eles. Por outro lado, a Irmandade Muçulmana buscou se firmar através de serviços sociais, especialmente nas áreas em que o Estado estava menos presente. Como acontece em casos semelhantes de outros movimentos islamistas, a liderança da Irmandade Muçulmana buscou ganhar apoio social mais amplo e se afastar de uma postura mais extremista. Contudo, um afastamento radical dos princípios da organização poderia implicar uma alienação da própria liderança em relação aos interesses dos integrantes da Irmandade. Nesse caso, a intensidade das preferências dos integrantes impôs limites às reformas propostas por alguns membros. Em momentos de maior radicalização, a liderança pragmática foi eclipsada por figuras carismáticas mais radicais, como foi o caso de Sayyid Qutb. 
Tal interação vai além do âmbito das escolhas racionais e de estratégias. Podese dizer que a Irmandade Muçulmana passou por um processo de socialização em que novos valores e crenças foram introduzidos na organização. Não seria correto afirmar que o interesse da liderança da Irmandade Muçulmana em se engajar na política egípcia seja apenas uma estratégia cínica desprovida de conteúdo. Houve uma transformação de ideologia e de valores, resultado desse longo processo. É possível pensar que a experiência de debates e interações entre integrantes da Irmandade Muçulmana e outras figuras políticas tenha afetado mutuamente cada lado. Nesse sentido, a participação da Irmandade Muçulmana no processo político não somente engendrou novas estratégias como também criou a necessidade de debates internos sobre os objetivos últimos e as crenças da organização.

Assim sendo, a análise da trajetória da Irmandade Muçulmana, de sua criação até a primeira década do século XXI, demonstra que a participação política resultou em mudanças importantes para a retórica e para as práticas da organização. Ao passo que muitos estudos enfatizam como as condições políticas e institucionais colaboraram com a moderação de movimentos mais radicais, o presente estudo buscou enfocar um aspecto mais limitado: o escopo de ação dos movimentos islamistas. Não se trata de dizer se a Irmandade Muçulmana abraçou valores democráticos ou não. Mas os mesmos mecanismos que funcionaram para a moderação da Irmandade são aqueles que delimitaram o escopo de ação do grupo a uma realidade política e social específica. A inserção da Irmandade Muçulmana em um espaço político, com regras e valores específicos, contribuiu para tal processo. O compromisso da organização para com grupos e movimentos nacionais influenciou a maneira como ela entende seu lugar na política egípcia e regional. Mais do que uma entidade abstrata e homogênea, a Irmandade Muçulmana é um grupo composto por indivíduos que pertencem a outros grupos e movimentos. São indivíduos que possuem múltiplas identidades, mas que, em última instância, reconhecem-se como egípcios. O Egito, ao contrário de outros países na região, tem uma história institucional mais consolidada. Suas fronteiras políticas, a despeito dos laços identitários que ligam os egípcios à região, são bem consolidadas (DAWISHA, 2003). As divisões internas, apesar de serem profundas, não criaram nenhum movimento separatista relevante. O Egito não é um país dependente de uma figura política forte que une grupos diversos que, de outra maneira, tenderiam a se dispersar. Tal realidade política e social do Egito é fundamental para entender a trajetória de "nacionalização" da Irmandade Muçulmana. 
Como mostra John Hutchinson (2005), movimentos transnacionais sempre coexistiram com Estados-nações. Apesar dos estudos tradicionais nas relações internacionais reconhecerem os Estados como os únicos atores legítimos no sistema internacional, esses nunca foram os únicos atores. Desde o início do período contemporâneo, movimentos nacionalistas coexistiram com movimentos transnacionais. Dessa forma, não é a existência de tais movimentos transnacionais uma prova da perda de importância do princípio do nacionalismo no sistema internacional contemporâneo. Apesar de o Estado-nação não ser o único ator no sistema internacional, ele ainda continua a ser o mais importante. No caso da Irmandade Muçulmana, ela não surgiu no final do século XX, quando movimentos islamistas transnacionais ganharam destaque nos estudos acadêmicos. Como foi apontado, ela surgiu em 1928, no mesmo período de gestação do nacionalismo pan-arabista e dos nacionalismos estatais no Oriente Médio. O engajamento da Irmandade em outros países ocorreu concomitantemente aos esforços das lideranças políticas dos países do Oriente Médio para conseguir a independência frente às potências europeias. Nesse sentido, a Irmandade Muçulmana é mais antiga que muitos países na região. Portanto, o estudo da trajetória da Irmandade Muçulmana, uma organização que, em sua origem, pregava abertamente o transnacionalismo, aponta para algumas razões por conta das quais há uma grande pressão para a nacionalização de organizações semelhantes em longo prazo.

No nível sistêmico e interestatal, não há previsão de que o princípio do nacionalismo será substituído por algum outro princípio. Isso porque, para ser reconhecido como ator político legítimo detentor de algum território, as entidades políticas precisam ser reconhecidas pelos outros atores no sistema internacional. Como mostra James Mayall (1999), tradicionalmente, há a interpretação de que a sociedade internacional é composta por Estados independentes e soberanos; e de que eles formam uma sociedade devido ao fato de eles reconhecerem cada um enquanto entidades legítimas e soberanas. Ainda que a soberania seja uma ideia fluida e que constantemente entra em contradição com o princípio da autodeterminação, em última instância, o reconhecimento pelos outros atores do sistema internacional importa. Isso implica uma mudança sistêmica do princípio legítimo que ordena o sistema internacional. O que, por si só, é uma tarefa considerável.

No âmbito inter-humano, os aspectos nacionais e transnacionais são menos evidentes. Por um lado, as atividades da Irmandade Muçulmana nunca estiveram limitadas pelas fronteiras estatais. Integrantes da Irmandade transitam através de fronteiras, coordenam ações e agendas com grupos em outros países e se engajam 
em causas regionais. Mas, por outro lado, o comportamento e a ideologia da Irmandade foram moldados com a interação com o Estado e a sociedade egípcia. Como argumenta Carrie Wickham (2013), a participação política foi a responsável pelas mudanças de comportamento e ideológicas da Irmandade, mais do que qualquer outro fator externo. Foram os arranjos institucionais, as relações de poder com o regime egípcio e a busca por apoio na sociedade que moldaram a natureza da Irmandade Muçulmana Egípcia.

\section{Conclusões}

O presente artigo tentou mostrar que a ação política da Irmandade Muçulmana se volta tanto para o espaço nacional como internacional, o que caracteriza a organização em sua origem com “cores” tanto nacionais quanto transnacionais. Essa situação particular fez com que Abd al-Fattah El-Awaisi (1998) constatasse que:

A sociedade da Irmandade Muçulmana foi, e ainda é, transnacional, ao mesmo tempo em que é nacional. Por um lado, ela inevitavelmente se expandiu para além de seu centro de origem no Egito, e, por outro lado, a invocação da questão Palestina na política Egípcia ajudou a definir a diferença da Irmandade Muçulmana com outros grupos, principalmente os nacionalistas. Deste modo a Ikhwan [a Irmandade Muçulmana] concretizou e definiu sua base de apoio e apelo dentro da política egípcia. A interação entre a política doméstica e a transnacional se reforçaram mutuamente. (EL-AWAISI, 1998, p. 205, tradução nossa) ${ }^{10}$

Entretanto, ao longo do século XX, aspectos nacionais ganharam maior relevância e a ação política da organização passou a se direcionar à dinâmica nacional egípcia. Portanto, a Irmandade Muçulmana não pode ser descrita como um movimento transnacional em sentido estrito, pois cada ramificação permanece política e historicamente vinculada aos seus respectivos Estados nacionais e, aparentemente, não pretendem transcender essas fronteiras. Apesar da ideologia de Hassan al-Banna pregar a união de todos os muçulmanos, fatores políticos foram fundamentais para a conformação da Irmandade Muçulmana ao cenário

10 "The Muslim Brotherhood society was, and remains, transnational as well as national. On the one hand, it inevitably expanded beyond its originating centre in Egypt, and, on the other hand, the invocation of the Palestine question in Egyptian politics helped to define the Muslim Brothers's [sic] differences with other groups, mainly nationalists. In this way the Ikhwan solidified and defined its base of support and appeal within Egyptian politics. The interaction between domestic and transnational politics was mutually reinforcing." 
nacional egípcio. Ainda que ela possua uma identidade que a vincule à população da região, a atuação política do grupo paulatinamente se restringiu ao Egito. Como observa Mona El-Ghobashy (2005), o contexto institucional teve grande importância nas mudanças pelas quais a Irmandade Muçulmana passou desde a sua criação. Aspectos ideológicos tiveram que ser adaptados às novas realidades políticas e sociais do Egito a fim de que a organização preservasse a sua relevância social. A situação perante Israel é emblemática. Se em 1936 e em 1948 a Irmandade Muçulmana egípcia teve um papel ativo na Palestina, em 1967 e em 1973, ela não tomou parte dos conflitos, ainda que condenasse as ações de Israel.

Cabe ainda nesta conclusão aludir à situação atual da Irmandade Muçulmana após os protestos de 2011 que levaram à queda de Mubarak no Egito. A Irmandade Muçulmana, embora não representasse a maioria dos egípcios, era o partido mais bem organizado comparado aos inúmeros grupos que surgiram desde 2011 e, dentre todos, era um dos que tinha maior capacidade de mobilização social. A Irmandade, que não participara ativamente dos protestos, saiu fortalecida politicamente após a queda de Mubarak, e através do Partido Liberdade e Justiça, ela conseguiu maioria nas eleições parlamentares e elegeu o seu candidato à presidência, Mohamed Morsi em 2012. Cabe destacar aqui que, mesmo promovendo uma agenda política com referências religiosas, Morsi buscou legitimar o governo através de argumentos que evocavam a unidade nacional.

Contudo, o que se observou nos meses seguintes foi a incapacidade tanto da Irmandade quanto da oposição de estabelecer uma frente coesa. Por um lado, o governo se distanciava dos outros partidos e adotava gradativamente uma postura autoritária. Por outro lado, a oposição, fragmentada e heterogênea, impacientavase com a estagnação econômica e a situação social precária. Com isso, novos protestos eclodiram em 2013, e os militares despontaram para determinados setores como um mal menor diante da ameaça de caos.

Em julho de 2013, uma junta militar depôs e prendeu o presidente Morsi, encerrando a breve experiência democrática egípcia. Semelhante ao que ocorrera no governo de Nasser, a corte egípcia baniu a Irmandade Muçulmana e ordenou o confisco de suas propriedades (ADULLAH, 2013). Com isso, a Irmandade muçulmana não somente está impossibilitada de participar da política egípcia por vias institucionais legais, como também passa por uma situação delicada no que diz respeito à sua própria sobrevivência enquanto movimento social.

No quinto aniversário da "Revolução de Lótus", esses acontecimentos evidenciam que o regime instaurado pelos Oficiais Livres não foi desmantelado 
após a queda de Mubarak. Mas, por outro lado, a história da Irmandade Muçulmana leva a crer que, a despeito da perseguição, a organização ainda terá um papel relevante na sociedade egípcia nos anos vindouros.

\section{Referências}

ABDULLAH, Al-Arian. What's next for the Muslim Brotherhood?. In; Washington Report on Middle East Affairs. Oct.-Nov, v.30, 2013.

AL-AWADI, Hesham. In pursuit of legitimacy: The Muslim Brothers and Mubarak 19822000. New York: Tauris Academic Studies, 2004.

ANDERSON, Benedict. Comunidades imaginadas: reflexões sobre a origem e a difusão do nacionalismo. São Paulo: Companhia das Letras, 2008.

ASAD, Talal. Religion, Nation-State, Secularism, In: VEER, Peter Van Der; LEHMANN, Harmut (Ed.). Nation and religion: perspective on Europe and Asia. Princeton: Princeton University Press, 1999.

AYALON, Ami. (Ed.). Middle east contemporary survey. Oxford: Westview Press, 1992. XVI v.

AYOOB, Mohammed. The many faces of political Islam: religion and politics in the muslim world. Ann Arbor: The University of Michigan Press, 2008.

AYUBI, Nazi. The political revival of Islam: The case of Egypt. In: International Journal of Middle East Studies. v. 12, n.4, p. 481-499, dec. 1980. doi: 10.1017/S0020743800031263. AYUBI, Nazih. Government and the State in Egypt Today. In: TRIPP, C.; OWEN, R. (Ed.) Egypt under Mubarak. London: Routledge, 1989. p. 1-21.

BAKER, Raymond William. Sadat and after: struggles for Egypt's political soul. Cambridge: Harvard University Press, 1990.

BREUILLY, John. Nationalism and the State. Manchester: University of Chicago Press, 1993. BREUILLY, John. Abordagens do Nacionalismo. In: BALAKRISHNAN, Gobal (Org.). Um mapa da questão nacional. Rio de Janeiro: Contraponto, 2000. p. 155-184.

BURGAT, François. Face to face with political Islam. 2. ed. London: I. B. TAURIS, 2005. COMMINS, David Dean. Hasan al-Banna. In: RAHNEMA, Ali (Ed.). Pioneers of Islamic Revival. London: Zed Press, 1994. p. 125-153.

DAWISHA, Adeed. Arab Nationalism in the Twentieth Century: from triumph to Despair. Princeton: Princeton University Press, 2003.

EL-AWAISI, Abd al-Fattah. The Muslim Brothers and the Palestine question 1928-1947. London: I.B. Tauris, 1998. 
EL-GHOBASHY, Mona. The Metamorphosis of the Egyptian Muslim Brothers. In: Journal of Middle East Studies. v. 37, pp. 373-395, 2005. doi: 10.1017/S0020743805052128.

FULLER, Graham E. The Spectrum of Islamic Politics. In: MARTIN, Richard; BARZEGAR, Abbas. Islamism: Contested Perspectives on Political Islam. Stanford: Stanford University Press, 2010.

GORDON, Joel. Nasser's blessed bovement: Egypt's Free Officers and the July Revolution. Cairo: American University in Cairo Press, 1996.

GURSES, Mehmet. Islamists, democracy and Turkey: a test $\mathrm{f}$ the inclusion-moderation hypothesis. In: Party Politics. v. 20, n. 4, p. 646-653, 2014. doi: 10.1177/1354068812448688. HOURANI, Albert. Uma história dos povos árabes. São Paulo: Companhia das letras, 2006. HUTCHINSON, John. Nations as Zones of conflict. London: Sage, 2005.

IBRAHIM, Saad Eddin. Egypt, Islam and democracy: critical essays. Cairo: American University in Cairo Press, 2002.

KEPEL, Gilles. Jihad: the trail of Political Islam. Tradução Anthony F. Roberts. Cambridge: Belknap Press of Harvard University Press, 2002.

KEPEL, Gilles. Muslim extremism in Egypt, the Prophet and Pharaoh. Tradução Jon Rothchild. Berkeley: University of California Press, 2003.

LEFEVRE, Raphael. Ashes of Hama: the Muslim Brotherhood in Syria. Oxford: Oxford University Press, 2013.

MAYALL, James. Sovereignty, Nationalism, and Self-determination. In: Political Studies. v. 47, n. 3, pp. 474-502, 1999. doi: 10.1111/1467-9248.00213.

MEIJER, Roel; BAKKER, Edwin. Introduction. In: MEIJER, Roel; BAKKER, Edwin. The Muslim Brotherhood in Europe. New York: Columbia University Press, 2012.

MITCHELL, Richard P. The Society of the Muslim Brothers. New York: Oxford University Press, 1969.

MUNSON, Ziad. Islamic mobilization: social movement theory and the Egyptian Muslim Brotherhood. In: The Sociological Quaterly. v. 42, p. 487-510, 2001. doi: 10.1111/j.1533-8525.2001.tb01777.x

RANKO, Annette. The Muslim Brotherhood and its Quest for Hegemony in Egypt: state-discourse and Islamist counter-discourse. Springer VC, 2015.

ROY, Olivier. The transformation of the Arab World. In: Journal of Democracy. v. 23, n. 3, julho 2012. Disponível em: < http://www.journalofdemocracy.org/article/ transformation-arab-world > . Acesso em: 13 Maio 2015.

SHEPARD. William E. Sayyd Qutb’s Doctrine of Jahiliyya. In: Middle East Studies. v. 35, n. 4, pp. 521-545, 2003. 
SULLIVAN, Denis Joseph; ABED-KOTOB, Sana. Islam in contemporary Egypt: civil society Vs. the State. Londres: L. Rienner Publishers, 1999.

TEITELBAUM, Joshua. The Muslim Brotherhood in Syria, 1945-1958: founding, social origins, ideology. In: Middle East Journal. v. 65, n. 2, p. 213-233, 2011. doi: 10.3751/65.2.12. WEISMANN, Itzchak. Democratic Fundamentalism? The practice and discourse of the Muslim Brothers movement in Syria. In: The Muslim World. v. 100, p. 1-16, 2010.

WICKHAM, Carrie Rosefsky. The Muslim Brotherhood: evolution of na Islamist Movement. Princeton: Princeton University Press, 2013.

WIKTOROWICZ, Quintan. Introduction: Islamic Activism and Social Movement Theory. In: WIKTOROWICZ, Quintan (ed.). Islamic Activism: a social movement theory approach. Bloomington: Indiana University Press, 2004.

ZAHREDDINE, Danny; LASMAR, Jorge Mascarenhas; TEIXEIRA, Rodrigo Corrêa. O Oriente Médio. Curitiba: Juruá. 2011.

ZOLLNER, Barbara. The Muslim Brotherhood: Hasan al-Hudaybi and Ideology. New York: Routledge, 2009. 